\title{
Targeting Th2-typified immune responses to prevent immunopathology in rheumatic diseases: belittled therapeutic strategies?
}

\author{
Frederique M Moret, ${ }^{1}$ Timothy R D J Radstake, ${ }^{1,2}$ Joel A G van Roon ${ }^{1,2}$
}

Although Th2-associated immune responses have been well defined in atopic diseases and parasitic infections, their potential contribution to immunopathology in rheumatic diseases has scarcely been recognised. This is probably related to the clear predominance of Th1/Th17 over Th2 cells in a number of rheumatic diseases, such as rheumatoid arthritis (RA), psoriatic arthritis and primary Sjögren's syndrome (pSS). Also, whereas a clear role for Th1/Th17 activity in immunopathology has been clearly demonstrated in these diseases, Th2-related phenomena such as $\mathrm{IgE}$ production are hardly detected. Indeed, Th2-associated atopic conditions and Th2 cytokines like interleukin (IL)-4 and IL-10 were shown to inhibit Th1-induced inflammatory responses in these diseases. ${ }^{12}$ As a consequence the understanding of Th2-associated mediators, other than IL-4 and $\mathrm{IgE}$, in these and other rheumatic conditions and the potential to target these have been underevaluated. However, recent data show that immune activation by typical Th2-associated pathways, such as mast cell activation and histamine-induced responses, or Th2-typified key regulatory molecules, such as thymic stromal lymphopoietin (TSLP), IL-33 and IL-13, contribute to inflammation and immunopathology in several rheumatic diseases.

\section{MAST CELLS AND PATHWAYS DRIVING HISTAMINE RELEASE: TARGETS IN RHEUMATIC DISEASES}

Mast cells have been shown to have a detrimental role in allergic reactions and parasitic infections. In addition, mast cells have been shown to be increased at inflammatory sites in a plethora of rheumatic conditions, including RA, pSS, systemic sclerosis (SSc),

\footnotetext{
'Department of Rheumatology and Clinical Immunology, University Medical Center Utrecht, Utrecht, The Netherlands; ${ }^{2}$ Center for Molecular and Clinical Immunology, Laboratory of Translational Immunology, University Medical Center Utrecht, Utrecht, The Netherlands

Correspondence to Dr Joel A G van Roon, Department of Rheumatology and Clinical Immunology, University Medical Center Utrecht, PO Box 85500, Utrecht 3508 GA, The Netherlands; j.vanroon@umcutrecht.n!
}

spondyloarthropathies (SpA), dermatomyositis and eosinophilia-myalgia syndromes. ${ }^{3-8}$ Mast cells have also been shown to be important mediators in different experimental inflammatory (arthritis) models by secretion of proinflammatory mediators such as tumour necrosis factor $\alpha$ (TNF $\alpha$ ), IL-6, IL-8 and IL-17. In addition, inhibitors of histamine release such as salbutamol and cromolyn were shown to prevent joint destruction in immune complex-mediated arthritis. ${ }^{9} 10$ Recent data suggest that targeting of mast cell-associated pathways prevents inflammatory responses driven by the innate and acquired immune system. One such pathway may be prevention of immune activation through blockade of the histamine $\mathrm{H}_{4}$ receptor $\left(\mathrm{H}_{4} \mathrm{R}\right)$. The human $\mathrm{H}_{4} \mathrm{R}$ expression is largely restricted to cells of the human immune system (eg, mast cells, eosinophils, monocytes, dendritic cells, T cells) and mediates several proinflammatory effects on these cell types, including cytokine secretion and chemotaxis. ${ }^{11}$ Cowden et al ${ }^{12}$ add new insights into the mechanism of this receptor, demonstrating that specific targeting of the $\mathrm{H}_{4} \mathrm{R}$ by an orally administered receptor antagonist prevents joint inflammation and inflammation-induced destruction of cartilage and bone. Using different experimental arthritis models, they demonstrate that innate effector cells, such as neutrophils and monocytes (collagen antibody-induced arthritis model), and acquired effector cells, like Th17 cells (collagen-induced arthritis model), play critical roles. Previous studies using antagonists of the $\mathrm{H}_{1}$ and $\mathrm{H}_{2}$ receptors have not been successful in treating autoimmune diseases; however, these antagonists do not affect the $\mathrm{H}_{4} \mathrm{R} .{ }^{13}$ These findings indicate new therapeutic opportunities in RA, but also many other rheumatic diseases associated with increases in histamine and (upregulated) expression of $\mathrm{H}_{4} \mathrm{R}$, in particular given its restricted expression to immune cells. ${ }^{13}$

Histamine levels have been shown to be enhanced at inflammatory sites in several (rheumatic) autoimmune diseases, including multiple sclerosis, inflammatory bowel disease, RA, ankylosing spondylitis, psoriatic arthritis and SSc. Triggers of histamine release by mast cells include
IgE-dependent pathways but also many IgE-independent pathways. Increased $\operatorname{IgE}$ complexes and total serum IgE levels in various autoimmune diseases such as RA, pSS and systemic lupus erythematosus (SLE) are present in only a minority of patients ( $10-30 \%$ of the patients). To what extent antigen-specific IgE antibodies trigger mast cell activation and histamine release in rheumatic diseases remains to be demonstrated but this might play a role in at least a subgroup of patients. Activation of mast cells by crosslinking of the high-affinity $\operatorname{IgE}$ receptor results in high TSLP and IL-33 secretion by these cells. ${ }^{14}$ Both cytokines are upregulated in several rheumatic diseases and induce activation of mast cells, ${ }^{3} 16$ potentially contributing to a positive feedback loop in chronic inflammation by enhancing release of histamine and other proinflammatory mediators, like $\mathrm{TNF} \alpha$ and IL-17.

IgE-independent mechanisms that have been described to trigger degranulation and histamine release include immunoglobulin complexes, complement and free light chains. ${ }^{10}{ }^{17}$ Toll-like receptor (TLR)-mediated histamine release has also been suggested, although the data are not consistent, ${ }^{18}$ which is in contrast to data on numerous inflammatory mediators that are released upon TLR-induced mast cell activation (for instance, interferons and $\mathrm{TNF} \alpha) .{ }^{19}$ Despite the inconsistency of results for direct histamine release by TLR ligation, TLR-induced activation of fibroblasts, either directly or indirectly through release of proinflammatory cytokines (including IL-1 $\beta$ and TNF $\alpha$ ), induces release of cytokines, which like IL-33 and TSLP enhance histamine release. $^{20-22}$ In addition, recently it was demonstrated that TLR-induced activation of neutrophils promotes histamine production via a PI3 kinase-dependent mechanism. ${ }^{23}$ Likewise, it has been shown that cell types such as dendritic cells contribute to increased histamine levels during inflammation, although these cells may induce lower levels. ${ }^{13}$ It is interesting that activation of cells through triggering of the $\mathrm{H}_{4} \mathrm{R}$ requires much lower levels of histamine than with the $\mathrm{H}_{1-3}$ receptors ( 100-1000-fold). ${ }^{13}$ Collectively, the increased numbers of mast cells, enhanced levels of histamine and numerous triggers to activate these and other cells to release histamine suggest that new approaches targeting histamine-associated pathways, as indicated by Cowden et $a l^{12}$ and including inhibition of mast cell activation, hold promise in various rheumatic diseases. 
HISTAMINE $\mathrm{H}_{4}$ RECEPTOR: AN EXAMPLE OF TARGETABLE TH2 TYPIFIED AMPLIFIERS IN IMMUNOPATHOLOGY OF RHEUMATIC DISEASES

Recently, in (models for) RA, SpA, SSc and SLE, other pathways that have been typified as atopy/Th2-associated immune responses, including those driven by TSLP, IL-33 and IL-13, have been identified as targets for treatment in rheumatic diseases, extending the data of Cowden et al. ${ }^{12}$ Strongly enhanced levels of these cytokines facilitating proinflammatory responses are present in a much higher percentage of patients than is the case, for example, for IgE.

Recently, increased TSLP levels were reported in the synovial fluid of patients with RA in comparison with patients with osteoarthritis. $^{21} 24$ TSLP was shown to activate enhanced numbers of CD1c-expressing myeloid dendritic cells to robustly induce Th1 and Th17 activity in addition to Th2 activity. $^{2425}$ In support of a role in RA, TSLP in mice enhanced the severity of collagen-induced arthritis, associated with enhanced joint inflammation and destruction of cartilage and bone. Conversely, mice deficient in TSLP receptor displayed strongly reduced arthritis severity and immunopathology, associated with strong inhibition of evident Th17 activity and modest Th2 activity. ${ }^{26}$ In analogy to histamine, this illustrates that TSLP may be a target in atopic diseases, and also in autoimmune disease like RA, predominantly regulating Th17 activity.

Mediators like TSLP were also shown to play a role in rheumatic diseases apart from RA in which Th2/Th17 responses seem to be more prominent. Recently, it was demonstrated that in addition to epithelial cells and fibroblasts, mast cells in human SSc skin and lung fibrosis and in the bleomycin model of scleroderma overexpressed TSLP, ${ }^{22}{ }^{27}$ which in its turn can activate mast cells. ${ }^{16}$ In cultured skin fibroblasts, TSLP expression was induced upon TLR triggering. TSLP in the skin of patients with SSc induced profibrotic genes and intracellular signalling that overlap with those induced by IL-13 and transforming growth factor (TGF) $\beta$, both pivotal mediators in $\mathrm{SSc}^{27}$ In addition, TSLP was demonstrated to induce TGF $\beta$-dependent fibrosis induction. Furthermore, in TSLP receptor-deficient mice, bleomycin-induced fibrosis was significantly reduced in parallel with significantly reduced local expression of IL-13. ${ }^{22}$ Finally, TSLP might also be a link to IL-33 expression, which induces IL-13-dependent cutaneous fibrosis, ${ }^{28}$ as levels of IL-33 are raised in patients with SSc correlating with the extent of skin sclerosis and severity of pulmonary fibrosis. ${ }^{29}$ Since
TSLP has the capacity to enhance Th2 activity associated with IL-33 and IL-13 production in protease-allergen-induced airways inflammation, ${ }^{30}$ this indicates a potential TSLP-induced axis in SSc, contributing to fibrosis.

Other rheumatic diseases in which enhanced expression of IL-33 and IL-13 has been demonstrated include pSS, SpA and RA. ${ }^{20} \quad 31 \quad 32$ Serum levels of IL-33 were significantly raised in patients with pSS, especially in patients with interstitial lung disease. IL-33 significantly correlated with rheumatoid factor and anti-SSB autoantibody levels in pSS. ${ }^{31}$ Increased levels of IL-33 and IL-13 were also detected in the joints of patients with RA and have been shown to contribute to synovial fibroblast hyperplasia. ${ }^{20}$

The study by Cowden $e t$ al $^{12}$ (this issue of $A R D)$ demonstrates the beneficial effects of blockade of the $\mathrm{H}_{4} \mathrm{R}$ to prevent innate and acquired immune responses and thereby immunopathology in experimental arthritis. Recent data demonstrate that targeting of other Th2-associated mediators, like TSLP, IL-33 and IL-13, prevents inflammation and immunopathological processes such as fibrosis. Collectively, these data emphasise that targets previously considered relevant in Th2-associated diseases, should be evaluated to prevent specific immunopathological processes in rheumatic diseases such as SSc, RA, pSS, SpA and SLE. Clinical trials will be required to document how such strategies might fit into the current armamentarium to treat these diseases.

Contributors All authors contributed to the manuscript and approved the final manuscript.

\section{Competing interests None.}

Provenance and peer review Commissioned; externally peer reviewed.

To cite Moret FM, Radstake TRDJ, van Roon JAG. Ann Rheum Dis 2014;73:477-479.

Received 27 August 2013

Revised 12 November 2013

Accepted 24 November 2013

Published Online First 9 December 2013

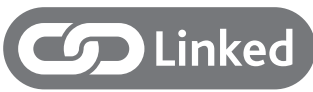

- http://dx.doi.org/10.1136/annrheumdis-2013203832

Ann Rheum Dis 2014;73:477-479.

doi:10.1136/annrheumdis-2013-204285

\section{REFERENCES}

Verhoef CM, van Roon JA, Vianen ME, et al. Mutual antagonism of rheumatoid arthritis and hay fever; a role for type 1/type $2 \mathrm{~T}$ cell balance. Ann Rheum Dis 1998;57:275-80.
2 Ghoreschi K, Thomas P, Breit S, et al. Interleukin-4 therapy of psoriasis induces Th2 responses and improves human autoimmune disease. Nat Med 2003;9:40-6.

3 Kashiwakura J, Yanagisawa $\mathrm{M}$, Lee $\mathrm{H}$, et al. Interleukin-33 synergistically enhances immune complex-induced tumor necrosis factor alpha and interleukin-8 production in cultured human synovium-derived mast cells. Int Arch Allergy Immunol 2013;161(Suppl 2):32-6.

4 Konttinen YT, Tuominen S, Segerberg-Konttinen M, et al. Mast cells in the labial salivary glands of patients with Sjogren's syndrome: a histochemical, immunohistochemical, and electron microscopical study. Ann Rheum Dis 1990;49:685-9.

5 Hugle $\mathrm{T}$, Hogan $\mathrm{V}$, White $\mathrm{KE}$, et al. Mast cells are a source of transforming growth factor beta in systemic sclerosis. Arthritis Rheum 2011;63:795-9.

6 Noordenbos T, Yeremenko N, Gofita I, et al. Interleukin-17-positive mast cells contribute to synovial inflammation in spondylarthritis. Arthritis Rheum 2012;64:99-109.

7 Shrestha S, Wershil B, Sarwark JF, et al. Lesional and nonlesional skin from patients with untreated juvenile dermatomyositis displays increased numbers of mast cells and mature plasmacytoid dendritic cells. Arthritis Rheum 2010;62:2813-22.

8 Seidman RJ, Kaufman LD, Sokoloff L, et al. The neuromuscular pathology of the Eosinophilia-Myalgia syndrome. J Neuropathol Exp Neurol 1991;50: 49-62.

9 Kneilling M, Hultner L, Pichler BJ, et al. Targeted mast cell silencing protects against joint destruction and angiogenesis in experimental arthritis in mice. Arthritis Rheum 2007;56:1806-16.

10 Lee DM, Friend DS, Gurish MF, et al. Mast cells: a cellular link between autoantibodies and inflammatory arthritis. Science 2002;297: 1689-92.

11 Walter M, Kottke T, Stark H. The histamine H(4) receptor: targeting inflammatory disorders. Eur J Pharmacol 2011;668:1-5

12 Cowden JM, Yu F, Banie H, et al. The histamine H4 receptor mediates inflammation and Th17 responses in preclinical models of arthritis. Ann Rheum Dis 2014;73:600-8

13 Stegaev V, Sillat T, Porola P, et al. Brief report: first identification of $\mathrm{H}(4)$ histamine receptor in healthy salivary glands and in focal sialadenitis in Sjogren's syndrome. Arthritis Rheum 2012;64:2663-8.

14 Soumelis V, Reche PA, Kanzler H, et al. Human epithelial cells trigger dendritic cell mediated allergic inflammation by producing TSLP. Nat Immunol 2002:3:673-80.

15 Hsu CL, Bryce PJ. Inducible IL-33 expression by mast cells is regulated by a calcium-dependent pathway. J Immunol 2012;189:3421-9.

16 Allakhverdi Z, Comeau MR, Jessup HK, et al. Thymic stromal lymphopoietin is released by human epithelial cells in response to microbes, trauma, or inflammation and potently activates mast cells. J Exp Med 2007;204:253-8.

17 Redegeld FA, van der Heijden MW, Kool M, et al. Immunoglobulin-free light chains elicit immediate hypersensitivity-like responses. Nat Med 2002;8:694-701

18 Varadaradjalou S, Feger F, Thieblemont N, et al. Toll-like receptor 2 (TLR2) and TLR4 differentially activate human mast cells. Eur J Immunol 2003:33:899-906.

19 Lappalainen J, Rintahaka J, Kovanen PT, et al. Intracellular RNA recognition pathway activates strong anti-viral response in human mast cells. Clin Exp Immunol 2013;172:121-8.

20 Hu F, Shi L, Mu R, et al. Hypoxia-inducible factor-1alpha and interleukin 33 form a regulatory circuit to perpetuate the inflammation in rheumatoid arthritis. PLoS One 2013:8:e72650. 
21 Ozawa T, Koyama K, Ando T, et al. Thymic stromal lymphopoietin secretion of synovial fibroblasts is positively and negatively regulated by Toll-like receptors/nuclear factor-kappaB pathway and interferon-gamma/dexamethasone. Mod Rheumatol 2007;17:459-63.

22 Usategui A, Criado G, Izquierdo E, et al. A profibrotic role for thymic stromal lymphopoietin in systemic sclerosis. Ann Rheum Dis 2013;72:2018-23.

23 Smuda C, Wechsler JB, Bryce PJ. TLR-induced activation of neutrophils promotes histamine production via a PI3 kinase dependent mechanism. Immunol Lett 2011;141:102-8.

24 Moret FM, Hack CE, van der Wurff-Jacobs KMG, et al. TSLP: a novel potent proinflammatory mediator that activates myeloid dendritic cells to stimulate Th1 and Th17 activity in rheumatoid arthritis [abstract]. Ann Rheum Dis 2011;70:A43-4. [conditionally accepted Arthritis Rheum 2013].
25 Moret FM, Hack CE, van der Wurff-Jacobs KMG, et al. Intra-articular CD1C-expressing myeloid dendritic cells from rheumatoid arthritis patients express a unique set of $\mathrm{T}$ cell-attracting chemokines and spontaneously induce Th1, Th17 and Th2 cell activity. Arthritis Res Ther 2013(15):R155-1.

26 Hartgring SA, Willis CR, Dean CE Jr, et al. Critical proinflammatory role of thymic stromal lymphopoietin and its receptor in experimental autoimmune arthritis. Arthritis Rheum 2011;63:1878-87.

27 Christmann RB, Mathes A, Affandi AJ, et al. Thymic stromal lymphopoietin is up-regulated in the skin of patients with systemic sclerosis and induces profibrotic genes and intracellular signaling that overlap with those induced by interleukin-13 and transforming growth factor beta. Arthritis Rheum 2013;65:1335-46.

28 Rankin AL, Mumm JB, Murphy E, et al. IL-33 induces IL-13-dependent cutaneous fibrosis. J Immunol 2010;184:1526-35.
29 Yanaba K, Yoshizaki A, Asano Y, et al. Serum IL-33 levels are raised in patients with systemic sclerosis: association with extent of skin sclerosis and severity of pulmonary fibrosis. Clin Rheumatol 2011;30:825-30.

30 Togbe D, Fauconnier L, Madouri F, et al. Thymic stromal lymphopoietin enhances Th2/Th22 and reduces IL-17A in protease-allergen-induced airways inflammation. ISRN Allergy 2013;2013: 971036.

31 Zhao L, Yao L, Yuan L, et al. Potential contribution of interleukin-33 to the development of interstitial lung disease in patients with primary Sjogren's Syndrome. Cytokine 2013;64:22-4

32 Theoharides TC, Zhang B, Kempuraj D, et al. IL-33 augments substance $P$-induced VEGF secretion from human mast cells and is increased in psoriatic skin. Proc Natl Acad Sci USA 2010;107: 4448-53. 